\title{
Influence of urban environment on wind-driven rain load on building facades
}

\author{
Xiaohai Zhou, ${ }^{\mathrm{a}, \mathrm{b} *}$, Aytac Kubilay ${ }^{\mathrm{a}}$, Dominique Derome ${ }^{\mathrm{c}}$, Jan Carmeliet ${ }^{\mathrm{a}}$ \\ ${ }^{a}$ Chair of Building Physics, ETH Zurich, Zurich, Switzerland \\ ${ }^{b}$ Laboratory of Multiscale Studies in Building Physics, Empa, Dübendorf, Switzerland \\ ${ }^{c}$ Department of Civil and Building Engineering, Université de Sherbrooke, Sherbrooke, Canada
}

\begin{abstract}
Wind-driven rain (WDR) is the largest moisture source that influences the hygrothermal performance of building envelopes. Accurate estimation of WDR load on building facades is very important for hygrothermal analysis of building envelopes. In this study, we use CFD models to investigate the influence of urban environment on WDR load and distribution on the building facades. The case study is a historical building located in the city center of Zurich. There is a very large difference between the WDR load and distribution on the building façade of the historical building when located in the urban environment or in the open field. For the same building, the WDR load can be five times larger in the open field than when located in an urban environment. Furthermore, the distribution pattern of WDR is also significantly changed by the presence of an urban environment. The decrease in WDR for the building in an urban environment is mainly due the reduction of the wind flow velocity especially in front of the historical building. Wind flow direction is significantly changed in the urban environment. Furthermore, compared to the CFD method, the empirical methods could be very inaccurate.
\end{abstract}

Peer-review under the responsibility of the organizing committee of the ICMB21.

Keywords: wind-driven rain load; urban environment, CFD simulaiton

\section{Introduction/Background}

One of the main factors affecting durability of buildings is moisture. Wind-driven rain (WDR) is the largest moisture source that influences the hygrothermal performance of building envelopes. Accurate estimation of WDR load on building facades is very important for hygrothermal analysis of building envelopes. WDR load on building surfaces can be estimated with (1) measurements, (2) semi-empirical methods, and (3) numerical simulation. Measurement of WDR is very time consuming, costly and site-specific. Although semi-empirical methods are fast ways of estimating WDR, they do not provide high spatial accuracy. By comparison, the numerical simulation of WDR with computational fluid dynamics (CFD) can determine the temporal and spatial distribution of WDR on the building façades accurately. In an urban environment, the WDR load on buildings can be strongly affected by façade details and the surrounding buildings. In most previous studies on WDR, the urban environment is simplified or absent. It is necessary to study WDR load on building facades in a real urban environment. In this study, we investigate WDR spatial distribution on one historical building in the city center of Zurich, Switzerland and compare with the WDR on the same historical building if located in the open field. The difference of WDR load and distribution in urban environment and open field are analyzed and discussed.

\section{Methodology}

\section{Numerical model for WDR simulation}

3D steady RANS with the standard k- $\varepsilon$ model is used for simulation of wind flow. A Eulerian multiphase (EM) model is used for simulation of the rain phase $[1,2]$. In the EM model, the rain phase is also viewed as a continuum. Each class of raindrop sizes is treated as a different phase as each group of raindrops of similar size interacts with the wind flow field in a similar way. This EM model has been validated against field measurements [1]. An overall description of WDR modeling is found in [3].

The simulation domain is located in the Zurich city center (Figure 1a). A 5-story historical building located at the Münsterhof square is used for this WDR study. The geometry of the historical building is shown in Figure 1b. The main façade of this building faces west. This historical building has an overhang to protect its façade against WDR. The geometrical details of this building is captured accurately with windows and sills, while the geometry of the other buildings is modeled in a simplified way keeping main volumes and roof shapes [as done in 4]. For comparison, the same historical building is considered in the open field using the same simulation domain without surrounding buildings.

\footnotetext{
* Corresponding author. 004158765 6012.xizhou@ethz.ch
} 

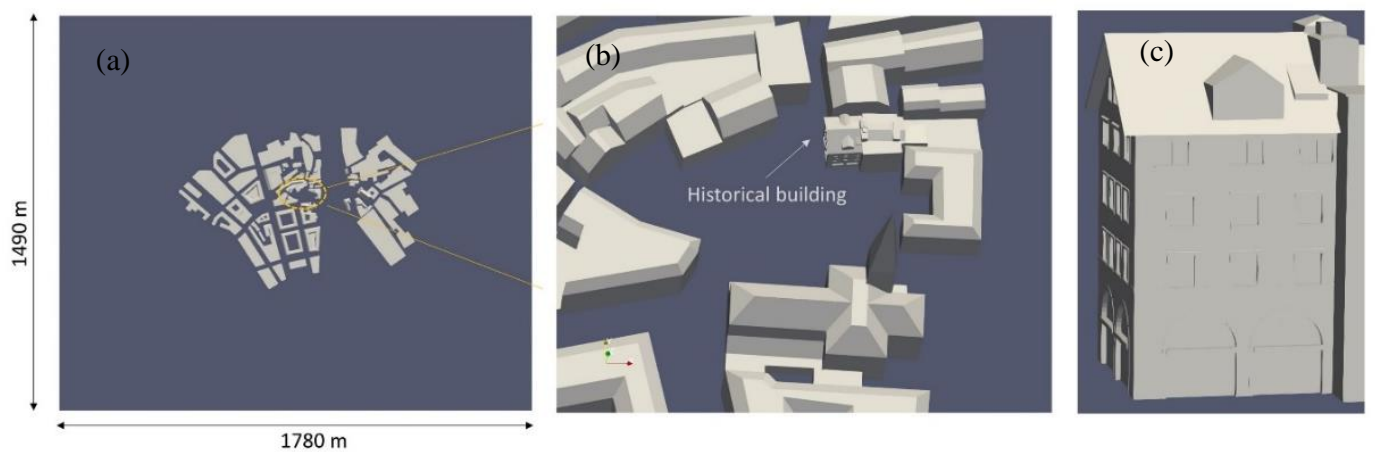

Figure 1. (a) Simulation domain of the study; (b) the historical building at the Munsterhof square; (c) a zoomed view of the historical building

\section{Results}

Fig. $2 \mathrm{a}$ and $2 \mathrm{~b}$ shows the distribution of catch ratio for a reference wind speed of $U 10=5 \mathrm{~m} / \mathrm{s}$, wind direction of 270 degrees (i.e. due west) and a reference rainfall intensity of $1 \mathrm{~mm} / \mathrm{h}$ on the façade for the historical building in the urban and open field environment. The catch ratio represents the ratio of WDR load on building façade to horizontal rain intensity. There is very large difference of WDR load and distribution on the building façade in urban environment versus open field. The WDR catch ratio for the building in the urban environment varies between 0.0 and 0.1 whereas the catch ratio for the building in the open field environment varies between 0.0 and 0.5 . The catch ratio at some locations on the façade can be up to five times larger in the open field than in the urban environment. In addition, the WDR load on the façade of the building in the urban environment has the largest value in the upper part of the façade whereas the largest WDR loads are at the lateral sides of the building in the open environment. The difference of WDR between the two cases is mainly due to the difference in the wind flow field. Wind flow velocity in the urban environment is significantly reduced and becomes much smaller in front of the historical building. Furthermore, wind flow direction is significantly changed in the urban environment. The protection effect of the overhang of the historical building is much larger when wind velocity is smaller. The calculated WDR load by empirical methods could be very inaccurate in the urban environment. For some empirical methods, the calculated WDR load in the urban environment could be more than three times larger than that from CFD (Fig. 2c).
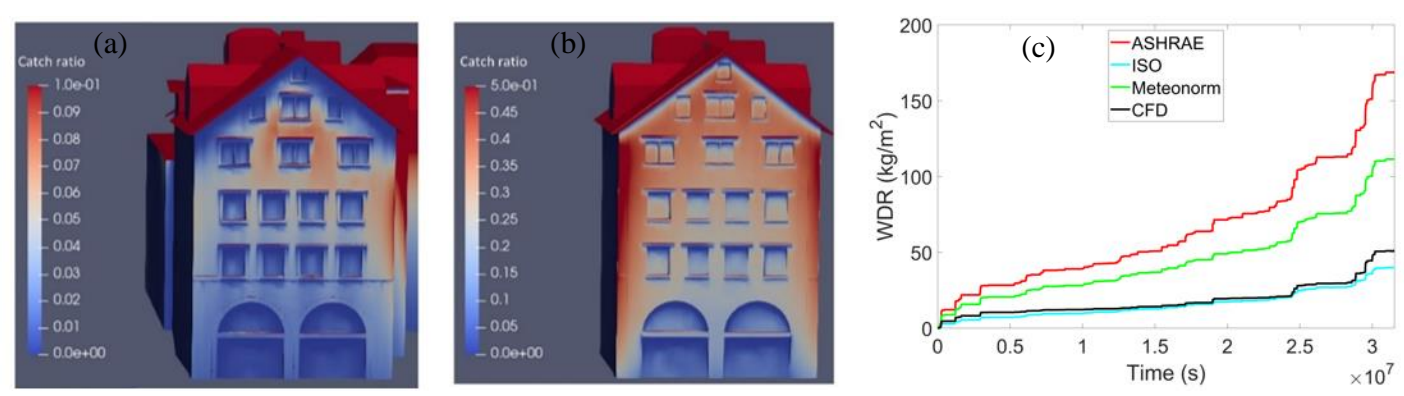

Figure 2. Catch ratio on the west facing building façade for wind speed $\mathrm{U} 10=5 \mathrm{~m} / \mathrm{s}$, wind direction $270^{\circ}$ and rainfall intensity $\mathrm{Rh}=1 \mathrm{~mm} / \mathrm{h}$ (a) case with the building in urban environment; (b) case with the building in the open field; (c) comparison of WDR load by semi-empirical and CFD methods

\section{Conclusions}

In this study, we investigate WDR on a building in the urban environment and in open field. There is very large influence of the urban environment on WDR load and distribution on this building. The complicated distribution of WDR load on the building façade makes it difficult to apply semi-empirical methods for estimating WDR on the building façade in the urban environment.

\section{References}

[1] Kubilay, A., Derome, D., Blocken, B., \& Carmeliet, J. (2013). CFD simulation and validation of wind-driven rain on a building facade with an Eulerian multiphase model. Building and environment, 61, 69-81.

[2] Kubilay, A., Derome, D., Blocken, B., \& Carmeliet, J. (2015). Numerical modeling of turbulent dispersion for wind-driven rain on building facades. Environmental Fluid Mechanics, 15(1), 109-133.

[3] Derome, D., Kubilay, A., Defraeye, T., Blocken, B., Carmeliet, J. (2017). Ten questions concerning modeling of wind-driven rain in the built environment, Building and Environment, 114, 495-506.

[4] Kubilay, A., Carmeliet, J., Derome, D. (2017). Computational fluid dynamics simulations of wind-driven rain on a mid-rise residential building with various types of facade details, J. Building Performance Simulation, 10, 125-143. 